Letras, Lima. 1977-79. (Nos. 86-87), 91-108.

\title{
La Sociología del drama moderno en Lukacs
}

\author{
JOSE I. LOPEZ SORIA
}

Los intentos del filósofo húngaro György Lukács (1885-1971) por constituir el status epistemológico de la sociología de la literatura son tan antiguos como su propio inicio en el filosofar. El planteamiento mismo del problema obedece a la necesidad de clarificar el trasfondo posibilitante de la obra literaria. En los años de juventud de Lukács la cultura centrceuropea atravesaba por una crisis de fundamentos como consecuencia del derrumbamiento de los pilares que hasta entonces la habían sostenido. No era ya posible para las viejas formas moldear la vida nueva. En estas circunstancias - no ajenas ciertamente al desmoronamiento de la estructura imperial de Auistria-Hungría te se dan las condiciones objetivas para que la conciencia caiga en la cuenta de las diferencias entre el alma y las formas, la vida y la obra. El hombre moderno se ha vuelto problemático. La cultura, hasta entonces esencialmente cerrada, se ha abierto. Y la problematicidad del hombre y la apertura de la cultura no pueden ya ser atrapadas por las viejas formas. La sociología de la literatura se presenta entonces como un camino hacia la construcción de una nueva cultura que responda y se adecúe a las exigencias del "hombre problemático". No es raro, por tanto, que en este esfuerzo por echar las bases de una nueva cultura esté siempre presente la cultura greco-latina como paradigma. La atribución de paradigmaticidad a las "culturas cerradas" no lleva, sin embargo, a Lukács a enfatizar la necesidad de reconstruirlas. El filósofo húngaro está convencido del cambio operado en la condición del hombre. El hombre se ha vuelto problemático $y$, por lo mismo, difícilmente encerrable en los moldes clásicos de las "culturas cerracias". De lo que se trata, pues, es de posibilitar una cultura para el hombre problemático. El pensar lukácsiano arranca de esta vivencia fundamental y desde ella se lanza a una terca búsqueda de caminos de salida. 
Porque la cultura tradicional --en una sociedad aristocratizante, todavía feudalizacia y sin una burguesía creadora- ha desembocado en un callejón sin salida. La vieja arisiocrazia de la tierra y la moderna burguesía financiera no pueden ofrecer -ni política ni culturalmente- un proyecto sccial capaz de agluiinar al resto de las clases sociales. La pequeña burguesía radicalizada intenta entonces llenar el vacíc colítico-cultural que se produce en el mundo austrohúngaro en las des primeras décadas del siglo XX. La primera reflexión de Lukács se insería preciscimente en este esfuerzo del radicalismo burgués por hacer del mundo el hogar para el hombre. Sabemos que el esíuerzo, en el caso concreto de Hungría, terminó en el fracaso. La pequeña burguesía radicalizada no supo - tal vez no pudo- tener en cuenia que, a sus espaldas, se iba gestando una nueva fuerza social -el proleiariadoque no se resignaba ya al papel de objeto pasivo del proceso histórico. La grandeza de Lukács -base de su ulterior reflexión filosófica- consistió en advertir primero esa presencia del proletariado y en adherirse después a sus intereses de clase. Por eso, si bien es cierto que el filosofar lukácsiano arranca de la vivenciación de la crisis desde las posiciones del radicalismo burgués (lo que supone ya un cambio en György Lukács, quien procedía de la más alta burguesía financiera), la profundidard y exiensión de esa primigenia vivencia llevan al hijo del banquero József von Lukács a identificarse con los postulados del movimiento obrero. Pero este segundo giro - cuyo primer paso podría ser la inscripción de Lukács en el Partido de los Comunistas de Hungría en diciembre de 1918 - quéda ifuera del objeto de nuestro análisis.

La finalidad de estas páginas es presentar la obra titulada A modern dráma tojlödésének története (Historia de la evolución del drama moderno), escrita por Lukács en 1906-07, reelaborada en 1908-09 y publicada por primera y única vez en húngaro en 1911. Sólo algunos parágrafos sueltos de este libro, que consta de 2 volúmenes y más de 1,000 páginas, han sido luego incluidos en ediciones en húngaro, castellano, alemán e italiano de las obras de Lukács. Forenc Fehér, discípulo de Lukács y miembro de la Escuela de Budapest, ha preparado una edición abreviada del mismo que será publicada en italiano. (En adelante usaremos Historia del drama para aludir a Historia de la evolución del drama moderno).

"En los años 1904-1907 -dice el mismo Lukács en el prólogo a Historia del drama-, como uno de los directivos de la Compañía Thália, seleccionador de obras y director de escena, etc. viví por dentro las cuestiones de las que se trata en este libro y solamente cuando tuve que escribirlas, cuando quise volver sobre las causas y las leyes de estas cuestiones, el libro se volvió puramente teórico y su forma estilística conceptual. A pesar de ello, los 
problemas aquí tratacios surgen por completo de la vida y siento a este libro en estrecha relación con ella y lo publico con la esperanza de que los lectores sientan también esta misma relación". El texto ro puede ser más claro. La reflexión teórica de Lukács sobre el drama es posterior a su experiencia teatral. En 1904 un grupo de jóvenes (Gyögy Lukács, Marcell Benedek y László Banoczi), a los que se une luego el director de teatro Sándor Hevesi, fundan la Compañía Thália, a imitación del Antoine Théâtre Libre de París y del Brahm Freie-Bühne de Berlín, para introducir en los ambienies escénicos budapestinos las modernas corrientes realistas de la dramaturgia. Después de cuatro años de funcionamiento la policía municipal obligó a los jóvenes a clausurar las representaciones aduciendo que no respetaban las disposiciones por permitir que se fumase durante las funciones. Se trataba naturalmente de un pretexto. Porque la Compañía Thália no sólo trastornó los modos clásicos de puesta en escena y llevó el teatro a los obreros, sino significó una crítica a la "Hungría histórica" que ni la aristocracia tradicional ni la moderna capa gentry estaban dispuestas a aceptar.

Con el cierre de Thália fracasa el primer intento de Lukács por participar creativamente en la transformación cultural y social de su país. Pero la participación en este grupo permitió al joven filósofo estudiar en la práctica la esencia del drama y definir el sentido que para él tenía el teairo. "Allí —en Tháilia; J.I.L.S.aprendí en la práctica qué era el drama y qué significaba para el drama el escenario; allí se desvaneció definitivamente mi creencia inicial de que milparticircación en la literatura pudiese consistir en un trabajo literario creativo".li La paricipación en Thália enseñó a Lukács que en la literatura podía tomar parte como teórico pero no como creador. Sus buenos dessos juveniles de escribir obras de teatro no llegaron nunca a realizarse. La correspondencia entre Lulács y Benedek, Bánoczi y Hevesi da testimonio de estos intentos fallidos. Pero de esia activiciad teatral y de una profunda meditación sobre ella nace la reflexión ieórica sobre el drama. El primer fruto es precisamente Historia del droma.

El libro reccge la herencia de no pocas lecturas (Kant, Dilthey, Simmel, Marx, etc.), ia actividad desarrollada en Thália y el conocimiento ganado en asiduas visilas a los ieairos de Budapest, Viena y Berlín. De Kant y de los kantionos Dilthey y Simmel aprendió Lukács la importancia de la exigencia científica. Junto a este prozeso de purificación científica se había descrrollado en Lukács la inclinación hacia la historia y la sociolcgía. La leciura aienta de Marx, aunque hecha a través de los ojos de Simmel, le fue convenciendo de la necesidad de buscar en la estructura y en la evolución de la sociedad el fundamento de la obra literaria. Más allá del chato positivismo del radicalismo burgués húngaro 
-en el que Lukács se sintió siempre "huésped tolerado"- y de la incipiente Escuela de Viena, se eleva Lukács $a$ un nivel de abstracción heredero del kantismo y de las corrientes de la filosofía de la vida.

La reflexión lukácsiona sobre el drama moderno comienza preguntando si existe en verdad drama moderno y cuál es su estilo. Se trata, en opinión de Lukács, de una cuestión eminentemente sociológica, pero no existía todavía una sociología de la literatura ya que los únicos ensayos a este respecto se limitaban a establecer conexiones un tanto epidérmicas entre el contenido de las cbras y las relaciones económicas. Y para Lukács "Lo verdaderamente social en la literatura es la forma". Sólo a través de la forma es posible causar efecto en el público, a pesar de que es.a verdad suele pasar inadvertida tanto para el público como para el creador. Porque la forma -tiempo, ritmo, relievamiento de unos aspectos y descuido de otros, disposición de luces y sombras, etc.es un factor de la vida psíquica del artista que actúa como posición frente a las cosas y frente a la vida. Toda vivencia, toda experiencia se da sub specie formae. "La verdadera forma del verdadero artista es algo constante que está a priori frente a las cosas y sin lo cual no se podría siquiera caer en la cuenta de ellas". La forma es la relación entre los diversos destinos de una misma época, pero es la vida la que determina esos destinos y esas relaciones. La vida es, pues, la generadora de las diversas concepciones del mundo que, a su vez, se expresan en las formas.

Esquematizando la estructura conceptual del mundo de la literatura y concretamente del drama, habla Lukács de dos series causales cuyo encuentro posibilita | el efecto de la obra sobre el público. Por una parte, las relaciones económico-culturales posibilitan determinadas concepciones de la vida; la forma, en cuanto a priori, se dirige a la vida para escoger de ella su materia. La obra, por tanto, no es otra cosa que la vida dotada de forma. Por otra parte, el público, en función de sus concepciones de la vida -trasunto también de las mismas relaciones económico-culturales-, está capacitado para recibir el efecto que las formas pueden producir. Pero el encuentro (efecto) de los dos extremos (obra y público) de estas dos series no es estático. El efecto de la obra en el público, que depende de cómo haya sido capaz la obra de dotar de forma a los aspectos totales de la vida que configuran al público mismo, suele repercutir en la obra, lo que a su vez posibilita un más profundo efecto en el público, y así hasta el infinito.

En función de estas reflexiones teórico-metódicas, que manifiestan en más de un paso la influencia de Kant, Dilthey y Simmel, define Lukács el drama como "una obra tal que trata de producir efecto en la masa reunida, a través de acontecimientos que se desarrollan entre hombres". El objetivo del drama, producir 
efecto en la masa, delimita las características de la obra dramática (brevedad, generalidad, simbolicidad). La brevedad exige que se escojan sólo alguncs aconlecimientos y que se presenten en sus rasgos fundamentales. El postulado de la generalidad -"sólo lo general puede influir sobre la masa"- excluye lo individual y lo particular. Lukács se refiere sólo a lo general de los sentimientos y de las voliciones, excluyendo la generalización intelectual. En cuanto a la forma, lo general debe expresarse de manera sensible y simbólica. "Por tanto, el efecto directo en la masa por una parte exige la generalización y simbolización del acontecimiento bosquejado, pero por otra, los límites determinados por la exiensión obligan también al drama a la simbolización, al resumen, a una visión desde lejos, a vista de pájaro". De ahí se sigue la necesidad de que el drama se reduzca a tipificar, es decir, a presentar tipos de hombres con los cuales pueden identificarse muchos individuos concretos.

La segunda parte de la definición, "a través de acontecimientos que se desarrollan entre hombres", exige que la naturaleza no desempeñe en el drama sino un papel secundario y que lo sobrenatural, si tiene que ser incluido, aparezca sólo como problemática humana. "El drama sólo en forma de acontecimientos sociológicos puede expresar los fenómenos metafísicos".

Después de estas delimitaciones generales se pregunta Lukács qué tipo de hombres y de acontecimientos son capaces de causar efecto dramático en el público y pueden, por tanto, ser materia del drama. "El drama es el poema de la voluntad, porque sólo en su voluntad y en las acciones nacidas de ella puede el hombre manifestar con energía inmediata sucesencia total". Siendo la lucha la manifestación más pura y más expresiva de la voluntad, puesto que sólo en la lucha se expresa la vida toda del hombre, el drama tendrá como materia la vida vista desde los conflictos que surgen entre los hombres. Pero la lucha dramática solamente puede ser lucha entre hombres, entre fuerzas al menos subjetivamente proporcionales. Si se quiere que intervengan fuerzas superiores (dioses) tienen que intervenir sólo a través de las fuerzas humanas. "El drama es una lucha con fuerzas tan tensas que simbolizan la vida toda del hombre". Por eso todo drama se orienta en último término a la tragedia. Y la tragedia no es otra cosa que el despliegue máximo de las fuerzas de un hombre en lucha con el destino, con el mundo que está fuera de él, sobre un problema central de la vida. El drama encuentra, pues, en la tragedia, su culminación. Un drama perfecto no puede ser sino tragedia.

Las paradojas del drama derivan de la falta de adecuación de los medios a los fines. El contenido del diama es la vida como totalidad, un universo cerrado en sí, completo y perfecto, pero los instrumentos que se tienen para expresar este contenido son 
demasiado limitados. Surge entonces la necesidad de estilización que comporta renuncia a la riqueza y multiplicidad de la vida para reducirse a lo general. De aquí derivan dos paradojas: "La naturaleza de la estilización obliga siempre al drama a mirar abstractamente a les hombres y en forma dialéctica sus conflictos; la naturaleza del efecto, sin embargo, le permile usar sólo símbolos elementales, sensibles y de efecto inmediato; la naturaleza de la materia (hombres vivos y sus acciones) se opone también a la tendencia absolutamente necesaria a la estilización". Dado que el drama se refiere a la vida como totalidad y que sólo puede hacerlo a través de hombres concretos y de acontecimientos seleccionados, su universalidad no puede ser de contenido o material, sino formal, no extensiva sino intensiva, en fin, abstracta, metafísi$c a$, simbólica y mística. La universalidad del drama no se refiere a la riqueza infinita de los fenómenos ni a las realizaciones sin número de posibilidades ilimitadas, sino a las conexiones e interdependencias de los fenómenos entre sí. "El orden, la mutua conexión compleja y múltiple de las cosas, y la necesidad inexorable de esta relación y el carácter sucesivo de las cosas, son algunos de los más imporiantes principios formales del drama". Los fenómenos dramáticos, en consonancia/con estos principios, no tienen otra realidad que su ser-en-reiación y ninguna otra relación es concebible en el caso del drama sino la relación causal. Se trata, por tanto, de una larga cadena de causas y efectos que encuentra su causa última fuera del drama mismo, en la visión del mundo y on la filosofía del autor. Así pues, la forma dramática exige que el drama se estructure aliededor de una determinada concepción del mundo que da unidad a la pieza aun cuando el espectador no sea consciente de su existencia.

"La totalidad y multiplicidad de la vida es expresable en el drama sólo de manera puramente formal". Hay, pues, que suplir la totalidad material por la formal, la totalidad extensiva por la intensiva, la totalidad empírica por la simbólica. Es decir, la categoría de totalidad en cuanto reunión extensiva (acumulativa) da lo empírico debe ser suplida por la de unidad cerrada o completitud. Se trata de algo cerrado, acabado en sí y, por lo mismo, de una nueva vida. Es precisamente la ilusión espontánea de completitud lo que da a la realidad incluida en el drama el carácter de vida. Nada falta allí, toda posibilidad ha sido considerada y para toda posible pregunta hay una respuesta. Para conseguir esta completitud es necesario acudir de nuevo a la estilización. Porque gracias a la estilización una vida concreta se convierte en "tipo de vida" y la lucha alrededor de un problema central de la vida de un hombre deviene punto axial alrededor del cual todo se reagrupa. Esto es precisamente lo que da la unidad cerrada al drama, pero ello es sólo imaginable en forma abstracta en fun- 
ción de la cosmovisión del autor. La forma dramática exige, por tanto. que el fundamento de la estilización postulada por la universalidad sea la cosmovisión, es decir, algo que antecede al drama mismo, un a priori que está fuera del mundo del drama en sentido estricto. Pero, por otra parte, la exigencia de causar efecto en la masa excluye la conceptualización abstracta. Así la completitud o unidad cerrada, nota caracterizante de la forma dramática, exige, de un lado, que el drama se apoye en algo que está fuera de él (la cosmovisión) y, de otro, excluye la posibilidad de que exista algo fuera de él. La cosmovisión que sirve de fundamento al drama es, pues, abstracta y conceptual en cuanto al contenido, pero en cuanto a la forma es lo contrario. Se introduce dentro del drama, le da unidad inmanente, se expresa a través de símbolos y se concretiza en conflictos entre hombres concretos. La presencia de esta cosmovisión es poco evidente para el espectador, pero su ausencia se advierte de inmediato porque destroza la composición por más perfecta que ésta sea técnicamente.

A pesar de su concretez es el drama, por la presencia de la cosmovisión, el más abstracto de los géneros literarios y el más próximo a la filosofía. Pretende "hacer conscientes a las grandes masas acerca de los más profundos problemas de la vida con ayuda te símbolos inmediatos, y quiere despertar los más profundos sentimientos vitales en hombres muy diferentes $y$ primitivizados por el hecho de vivir en multitud".

Otra fuente de paradojas en el drama es la relación dialéctica entre lo abstracto y lo concreto. "La esencia de la paradoja está en que se trata de hombres vivos que actúan espontáneamente, pero dentro de marcos rígidamente abstractos". La paradoja es, no obstante, más apariencia que reale en el verdadero drama porque el personaje, aunque esté caracterizado con sus notas personales, es siempre un "tipo" humano y, por lo mismo, algo abstracto, si bien concretiza una manera de ser hombre. "El hombre del drama es siempre un tipo". Y a esta concepción permanecerá fiel Lukács hasta sus últimos escritos. En el hombre del drama el carácter y la acción no son realidades separables, aunque sus ritmos, distancias y estilizaciones parezcan contrarios. Carácter y acción guardan entre sí una relación dialéctica en cuanto que la acción es el destino del héroe y el héroe siempre se identifica con su destino. Sólo identificándose con su destino puede llegar el personaje a ser héroe. El destino se expresa técnicamente a través de la presión de la situación sobre el héroe, porque el destino no está en el personaje, lo adviene de fuera. "Así pues, el destino dramático puede describirse con exactitud sólo de manera negativa: es todo aquello que influye sobre la formación de la vida personal de cualquier personaje y que no se origina en su carácter". Precisamente el encuentre entre el carácter, que en cuanto 
expresión de la voluntad humana representa el principio de la libertad, y el destino, que simbolizado en la presión de la situación representa el principio de la necesidad, y la identificación entre destino y carácter significan el momento místico del drama.

Pero tanto el carácter como la acción son elementos expresivos de segundo orden en el drama. El elemento expresivo por excelencia en el drama es el diálogo. El diálogo en el drama es tema y elaboración, materia y forma al mismo tiempo, y de esta contradicción se siguen todas las exigencias formales y materiales de la forma dramática. Materia y forma están, pues, de nuevo en contradictoriedad conceptualmente insoluble. Porque si bien es cierto que el drama consta sólo de díálogos, aquello que hay que expresar - la vida misma- trasciende el marco de las posibilidades expresivas del diálogo. La paradoja consiste entonces en que el drama, por tener como elemento expresivo por excelencia el diálogo, tiene que expresarlo todo por la vía psicológica, pero toda expresión sólo psicológica es necesariamente arbitraria e insuficiente. No ignora Lukács que el drama puede producir sensaciones que están en el límite del éxtasis místico por medio de la representación de acontecimientos de carácter psicológico, pero Esto sólo se logra plasmando el evento social en el psiquismo de los hombres que actúan en el drama.

Después de estas reflexiones se plantea Lukács el problema de la relación entre drama y tragedi.a. Desde el prólogo a Historia del drama había ya apuntado que todo verdadero drama termina en tragedia. Se trata ahora de justificar esta afirmación. Del zarácter de completitud deriva la necesidad de que el drama desemboque en tragedia. Además "la conexión definitiva del drama y la tragedia se sigue "en realidad de la más intima esencia del dra$\mathrm{ma}$, del hecho de que la aventura que constituye su objeto significa la vida toda y esto es sólo accesible en el hombre trágico y sólo en su situación vital trágica". La vida es, en general, un todo en cuanto que cada acontecimiento de ella desarrolla u obstaculiza la vida toda; por eso cada acontecimiento es un episodio, un pormenor que recibe su verdadera significación sólo por su relación al todo. "La experiencia trágica es la única que, aunque es sólo parte del todo, simboliza sin embargo al todo; es la única que puede ser símbolo de la vida toda. El hombre trágico es el único tipo humano que es simbolizable por una aventura de su vida". No es trágico, por tanto, el hombre que está aún en desarrollo porque el desarrollo no es representable en el drama. Tampoco puede serlo el filósofo porque para el filósofo todo es sólo sintomático, el acontecer es para él episódico y los hechos no consiguen obligarlo. No es tampoco trágico el hombre inquebrantablemente religioso porque para él la muerte no es el fin de la vida. Puede ser trágico sólo aquel hombre que posee una cierta ética, 
aunque ésta sea subjetiva. En virtud de esa ética el hombre se siente hacedor de hechos y responsable por ellos. Al hombre ético los hechos no le acontecen como mera compañía. El hombre ético se siente afectado por los hechos.

Las ideas de Lukács sobre el horizonie de lo trágico (la tragicidad no fue nunca en Lukács un círculo cerrado sino un horizonte $Y$, por lo mismo, algo susceptible de ser trascendido) recogen, es cierto, la mejor herencia de Kierkegaard, pero son más bien fruto de la búsqueda angustiosa de la totalidad tan característica de la inteligencia austrohúngara. La decadencia del imperio de los Habsburgos se hacía cada día más evidente a la conciencia de la inteligencia magyar y austríaca. La añoranza del paraíso que se iba día a día perdiendo y la no posesión del nuevo paraíso -en 1909 no se vislumbraba aún en la doble monarquía el grupo social capaz de dirigir la crisis hacia el alumbramiento de una nueva sociedad-anidan en el fondo de las conciencias en forma de vivenciación trágica. Se siente que se está a un paso de la inmersión total en el momento trágico sin otear caminos de salida. No hay otra posibilidad para lo más lúcida de la inteligencia austrohúngara sino aferrarse a la tragicidad como forma de vida, como plenitud de la existencia. Este aferramiento a la tragicidad lleva a Lukács al suicidio espiritual y al borde del suicidio material. Pero la llegada al límite de la tragicidad le abrirá las puertas de la utopía siguiendo, primero, las huellas del franciscanismo y, desFués, del revolucionarismo interior dostoievskiano.

En el último parágrafo del capítulo general sobre el drama aborda Lukács el problemaeun tanto novedoso entonces, de la sociología de la literatura. Se abre así Lukács a una perspectiva de análisis de los fenómenos literarios que alcanzará su cima en su posterior reflexión sobre estética y concretamente en La peculiaridad de lo estético (que en la versión castellana lleva el título de Estética y consta de cuatro volúmenes) y en Ontología del ser social (última obra de Lukács, sin versión castellana todavía). Ya en el prólogo a Historia del drama -escrito en Berlín, cuando el filósofo húngaro asistía a las "Vorlesungen" de Simmel- había afirmado que lo social de la obra literaria estaba propiamente en la forma. Ahora comienza asentando que las cuestiones históricas, la sociología del drama, derivan de los problemas de la forma dramática. Lo cual no significa, como quería ya entonces el marxismo vulgar (Ferenc Fehér, en su inédito que incluimos en $E l$ joven Lukács y la Escuela de Budapest de próxima aparición, ha probado convincentemente la distancia que existe entre el primer Lukács y el marxismo vulgar de la IIa. Internacional), que de las da, pregnante y sólida?". Esta manera de plantear el problema toda la literatura, ni que se pueda explicar por completo la personalidad toda de Shakespeare, por ejemplo, a partir del análisis so- 
ciológico de su época. La pregunta que interroga por el carácter condicionante de lo social en el drama debe formularse de otra manera: "¿en qué tiempo o de qué forma es posible el drama? ¿cuáles son los estados de ánimo epocales que exigen la forma dramática como su forma de expresión verdaderamente adecuada, pregnante y sólida?". Esta manera de plantear el problema no excluye las capacidades personales, busca más bien profundizar en los condicionamientos sociales que posibilitan o impiden el despliegue de esas capacidades. En lo que respecta al estilo, la pregunta interroga por las circunstancias sociales que determinan el estilo de un arte particular. Con respecto al drama habría que preguntar si existe en la forma dramática un elemento tal que sea también elemento constitutivo del estado de ánimo de la época y del sentimiento común de la época en cuestión. En caso afirmativo, este elemento estaría evidentemente determinado por lo social.

Por otra parte, el objetivo fundamental del drama, producir efecto en una masa reunida a través de acontecimientos que se desarrollan entre hombres, está indicando ya una evidente intención social. Social es la masa reunida sobre la que se produce el efecto dramático, y social es la materia del drama en cuanto que se trata de acontecimientos sociales que se desarrollan exclusivamente entre hombres. Para que los acontecimientos (materia) produzcan efectos en los asistentes al teatro es necesario que sean típicos y que simbolicen el destino de la masa. Sólo entonces la masa siente expresados en esos aconteceres su propia vida. Para que exista el drama es, por tanto, necesario que haya un grupo de hombres capaces de recibir el efecto dramático y que se dé una cierta comunidad de ideas entre esos, hombres. La primera condición atiende a la necesidad de la preexistenia del teatro (en cuanto local y escenario) con respecto al drama. Sin teatro (local, escenario) no hay drama. El drama que no nace del escenario se vuelve intelectual. La segunda condición se refiere o la preexistencia de una cierta cultura de la sensibilidad. Es cierto que sin escenario no hay drama, dirá Lukács, pero la desnuda existencia del escenario no es causa sino condición del surgimiento del drama. Para que se produzca el drama hay que añadir algo; ese algo es la cosmovisión. "El drama surge del escenario si la visión del mundo del público y del escritor es tal que exige la forma dramática como expresión de su más íntima esencia, si la vivencia común a ambos es tal (la vivencia trágica) que puede ser expresada de la mejor manera en el drama y con absoluta perfección sólo en el drama".

¿Pero cuándo se da concretamente una situación de este estilo? Sólo cuando el mundo de sentimientos de un grupo humano es de tal naturaleza que permite ver la vida en forma de dialéctica de fuerzas que se aniquilan mutuamente con energía inquebran. 
table. Se trata, pues, de épocas de decadencia en las que las fuerzas en juego no pueden ya ser contenidas. Epocas, diríamos por nuestra parte, como las que estaba pasando Hungría precisamente cuando Lukács escribía estas reflexiones. Al transformarse en esos tiempos la vida en absolutamente problemática, se hace necesaria la desaparición de los antiguos valores. Nace entonces la ideología de la muerte bella $\mathrm{y}$, con ello, las mejores condiciones para el drama y la tragedia. Todo se vuelve problemático desde dentro. No se trata de fuerzas exteriores que problematicen la realidad, sino de la dialéctica interna de la realidad misma. "Toda cultura - dice Lukács diez años antes de inscribirse en el Partido de los Comunistas de Hungría - es dominada por una cierta clase; o más exactamente: la forma, el tiempo y el ritmo raacidos de las relaciones políticas y económicas y del modo de vida total de esa clase, determinan las formas de manifestación de esa cultura". Al convertirse en problemático ese fundamento se hace también problemático el dominio de la clase en cuestión sobre la cultura. La problematicidad afecta entonces a todas las manifestaciones culturales de la sociedad. La época dramática es, por tanto, la época heroica de decadencia de una clase. No en vano, recuerda Lukács, el drama es producto típico de aquellos países (Inglaterra, Francia, España) que han vivido a fondo el decaer de la nobleza. Shakespeare, Calderón, Lope, Corneille y Racine supieron recoger la profunda vivencia de la crisis y darle su forma artística más adecuada, la forma dramática. Y lograron recoger esa vivencia trágica porque acertaron a hacer del dolor la fuente de la felicidad tporgue no buscaron paliativos al sufrimiento, porque expresaron en la destrucción de la vida típica la vida como totalidad. Âsí el drama, devenido en tragedia, permite tomar conciencia del proceso vital y origina la dicha intelectual que posibilita oponerse a las fuerzas de la destrucción y entender al mismo tiempo su necesariedad. Porque sólo entendiendo la necesariedad de esas fuerzas es posible, para la clase social emergente, contrarrestar su efecto negativo y alumbrar la nueva sociedad. La tragedia, en virtud de la concentración, introduce además en la vivencia trágica riquezas e intensidades de la vida nunca antes manifiestas. De esta manera consigue la tragedia revelar, precisamente en la caída, la totalidad del hombre.

Después de estas reflexiones teóricas, que abren nuevas perspectivas a la sociología del arte, trata Lukács de definir las características tipificantes del drama nuevo. Asienta para ello un principio metodológico de la mayor importancia. Lukács no analiza el hecho mismo del drama sino los elementos apriorísticos que posibilitan ese hecho, pues en su opinión la esencia del drama no es determinable con ayuda de los hechos históricos o de las abstracciones que se deducen de ellos. Es necesaria la fundamenta- 
ción conceptuăl, ya que la historia tiende a descomponer todo acontecimiento en elementos nunca repetidos, individuales, atomísticos. La historia presenta como abstracción injustificada toda diferenciación de estilo rigurosamente serarable y se inclina a borrar las fronteras entre las diversas épocas a fin de mostrar todo como meramente transitorio. "Nosotros pretendemos aquí describir la historia del drama moderno, el desarrollo objetivo de aconteceres abstraídos de la realidad. Es necesario, por tanto, que tracemos previamente el marco dentro del cual ponemcs los límites en un sitio y no en otro, de una manera y no de otra".

Establecida esta posición metódica, heredera del neokantismo ambiental, tipifica Lukács el drama moderno como burgués. "El drama moderno es el drama de la burguesía; el drama moderno es drama burgués". El drama se convierte para la burguesía en arma de su lucha ideológica por el control político. "El drama burgués es el primero que surge de contradicciones conscientes de clase; el primero cuyo objetivo es expresar el modo de pensar y de sentir de una clase que lucha por la libertad y el poder, y las relaciones con las demás clases". Las características generales del drama moderno son, para Lukács, consecuencia lógica e histórica de este origen (téngase en cuenta que en Hisioria del drama, como atinadamente han señalado Fehér y Márkus, en ensayos que incluimos en el libro aún inédito El joven Lukács y la Escuela de Budapest, se advierte un constante paralelismo entre el método metafísico-existencial y el histórico).

No nos detenemos en las características del drama para no alargar nuestra exposición péro queremos subtaya: que el análisis lukácsiano se apoya en la relación problemátiça -que se anticipa a La teoría de la novela- entre la vida, concretamente el modo burgués de vida en cuanto prototipo de la vida moderna, y la posibilidad de su conformación (dación de forma). Más que los contenidos del drama moderno preocupa a Lukács el problema de las formas. (Este problema será nuevamente abordado, desde una perspectiva que hace pensar en un protcexistencialismo, en El alma y las formas y muy especialmente en el diálogo titulado "Acerca de la pobreza de espíritu"). Historia del drama es en realidad una presentación de la evolución de la forma dramática hecha en función de la relación problemática antes aludida. El proceso hacia el drama moderno se inicia con el drama clásico alemán y el drama de tendencia francés. Sigue después la tipificación de la obra de Hebbel y de la de Ibsen, creadora esta última de la tragedia burguesa. En los capítulos siguientes analiza el naturalismo en sus iniciadores (Goncourt, Zola, Becque, Strindberg), en el drama campesino (Anzengrüber, Tolstoi) y $\in$ n los ensayos de Antoine y Brahm en París y Berlín respectivamente. Termina el estudio del naturalismo con una reflexión sobre los alcances y limitaciones 
de esta tendencia (que criticará muy duramente en sus obras posteriores). Los esfuerzos por salir del naturalismo preparan ya el terzeno para la aparición del gran drama moderno de Paul Ernst (con quien Lukács mantuvo una larga y conflictiva amistad), BeerHofmann, Strindberg y Hauptmann. El libro concluye con un capítulo sobre la evolución de la literatura dramática húngara que contiene interesantes apuntamientos sobre la cultura de Hungría.

El primer libro de Lukács es hijo de un anticapitalismo romántico que no es sino la expresión de la posición de no reconciliación con la Hungría oficial. El anticapitalismo romántico, en el que Lukács coincide con buena parte de la inteligencia austrohúngara de la época, puede expresarse como relación problemática entre lo trágico y lo grotesco. Es grotesca la lucha de Lukács porque el filósofo húngaro -y buena parte de la inteligencia austrohúngara de finales del siglo XIX y comienzos del XX- está convencido de que la monarquía es ya una pura ilusión de líderes. Su lucha es contra algo fantasmagórico. Y es, además, trágica esa lucha grotesca contra lo inexistente porque no se vislumbra siquiera camino de salida. Las clases dominantes (antigua nobleza de la tierra y advenediza burguesía financiera) daban cada día más muestras de su incapacitación para gobernar. Las capas medias, recopiladoras asistemáticas del mundo de las ideologías, a pesar de estar en proceso de agrupamento alrededor de instituciones culturales y de revistas, no tenían una posición definida en el proceso de producción - no eran "clases fundamentales" en el sentido de Gramsci- y, por lo mismo, acudían a la política afanosas de llenar el vacio de poder desde da perspectivas que les ofrecía una conciencia ideológica incapqz de trascender el reformismo burgués. El proletariado finalmente, aún en proceso de constitución de clase en sí, era manejado por líderes socialdemócratas demasiado inclinados al pactismo. En realidad no había aún, objetivamente, camino de salida. Se sentía amenazante la espada de Damocles sobre el antiguo régimen. Se palpaban las negras paredes del túrel por el que atravesaba la hungaridad, pero ni un rayo de luz clumbraba los pasos. No quedaba, para la burguesía radicalizada $\mathrm{y}$ especialmente para la inteligencia, sino aceptar la oscuridad como compañera de viaje y aferrarse a la caída como forma de vida. De ahí el sentido profundamente trágico de la reflexión lukácsiana que no acierta a mostrar su rechazo de lo viejo sino en la forma de anticapitalismo romántico.

Lukács pretende hermanar el neokantismo formalista (que aprendiera ya en la universidad de Budapest en las lecciones de József Bánóczi) con la crítica de la cultura aprendida de Simmel, el historicismo de Dilthey y un cierto marxismo sociologizado. Pero esta armadura conceptual, este ensamblaje categorial está impulsado por una profunda vivencia que hemos definido como po- 
sición de no-reconciliación con el mundo de la cultura oficial. Diríase que se trata de la vieja oposición de Lukács frente al mundo gentry, pero extendida a todas las manifestaciones de la vida y de la cultura. Desde el punto de vista teórico, Lukács comienza a ver en el socialismo y en el sindicalismo soreliano el trasfondo metafísico de los movimientos ideológicos modernos. En la práctica, sin embargo, está aún lejos de poner en esas nuevas ideologías el ansiado camino de salida. Al referirse a las posibilidades dramáticas del socialismo considera que Shaw no llega a crear el drama socialista a pesar de que critica despiadadamente a las instituciones burguesas desde una posición socialista. La literatura socialista comienza con Gorki, pero el mismo Gorki no pudo escribir dramas sociales sino cuando era anarquista. Es la percepción vaga de la insoportabilidad del presente lo que lleva a Gor$\mathrm{ki}$, en opinión de Lukács, al socialismo. Naturalismo y socialismo se diferencian en que el primero trata de explicar los fenómenos desde las causas cercanas e inmediatas, mientras que el segundo descuida la importancia de lo individual para adentrarse en causas más profundas y objetivas que transcienden al individuo. "No sería muy exagerado decir que toda la concepción marxista no es otra que la visión de un horizonte infinitamente lejano, tan lejano que la mirada que se pierde en lejanías apenas puede advertir las diferencias de ciertos pormenores". Aun cuando socialismo y naturalismo se diferencian en muchos aspectos, coinciden ambos en el rechazo a las fuerzas sociales que unen a los hombres y en el deseo de la eliminación de ellas. Artísticamente se identifican en el esfuerzo por mostrar, con claridad despiadada, lo malo y deforme de nuestra sociedad.u Eninalexplicación de esa deformidad y en la naturaleza del deseo de su destrucción vuelven nuevamente a separarse naturalismo y socialismo. "Para expresarlo con terminología marxista: el naturalismo es el adecuado instrumento de expresión de la ideología pequeño-burguesa; lo que significa lo mismo, aunque desde otro punto de vista, que lo que hemos afirmado arriba, es decir, que han comenzado a dejarse oir los deseos que nos consumen en una búsqueda del fin sin objetivo, oscura y estéril".

Ya desde entonces considera Lukázs que el marxismo es una síntesis, la síntesis más rigurosa que haya habido desde el catolicismo medieval. Pero esta síntesis es más capaz de influir en las convicciones políticas y sociales que en el arte. A nivel artístico el marxismo, por seguir una cierta dogmática, se aleja del hombre concreto para buscar la monumentalidad como expresión de la energía incontenible del movimiento obrero. De los sentimientos socialistas no ha surgido aún arte. Y es natural que así sea -dirá Lukács para escándalo de los socialistas- porque no puede haber ningún tipo de artes cuyos temas y motivos están inspirados 
en estos sentimientos. Podría, sin embargo, existir un cierto arte socialista si estos sentimientos consiguen atrapar la forma, si el sentir socialista encuentra su forma adecuada. Pero una manifestación artística no es socialista porque lo sean sus temas y motivos. Para Lukács el problema está en si "la maravillosa dialéctica del marxismo es en genercl transferible al drama, pero es imposible que hoy sea transferible. El drama es la dialéctica de las voluntades humanas y todo lo que no se manifiesta de esta manera es inutilizable para el drama. La esencia de la estilización dramática consiste en que un hecho de un hombre expresa toda la esencia de ese hombre, toda su vida, y es cierto que esto es tanto menos posible cuanto más actúan los hombres solamente en relaciones sociales". Para que un hecho pueda representar a un hombre es necesario que esté fuera de las relaciones sociales, pero si las fuerzas sociales son tales que no permiten a nadie escaparse de ellas, entonces no es posible el drama. Lo dramático puede ser dialéctico sólo en sí mismo. Para los socialistas los procesos históricos no son dramáticos por ser transitorios, "para el sentir socialista esos conflictos no son de validez eterna, no son metafísicamente necesarios $y$, por lo mismo, no son trágicos". Porque la tragicidad consiste en que la destrucción de algo es necesario y en que esa destrucción necesaria es símbolo y signo de la vida toda.

Estas reflexiones, que escandalizaron ya entonces $y$ siguen escandalizando a no pocos socialistas, significan por parte de Lukács una primera toma de distancia con respecto al socialismo de la IIa. Internacional. $\mathrm{No}$ se trata de una recusación del socialismo de Marx y Engels, al que Lukács ya se había acercado por entonces, sino de la interpretación mecanicista - la total disolución del individuo en la sociedad-que del pensamiento marxista hicieran los prohombres de la IIa. Internacional. Frente a esta posición, Lukács subraya la permanencia del individuo, especialmente del individuo devenido en persona moral y libre. Porque lo que Lukács busca, ya desde sus primeros escritos, es el despliegue total de las posibilidades humanas dentro de una comunidad de personas morales y libres. Que esa comunidad anhelada por Lukács no era precisamente la sociedad burguesa es algo que queda totalmente claro para el lector atento de sus obras de juventud. No queremos con ello afirmar que hubiese ya en Lukács una conciencia clara con respecto al objetivo de la búsqueda. Pero sí es evidente que su vieja posición de no reconciliación estaba llevando al filósofo a una actitud de rechazo total del modo burgués de vida. Pocos años más tarde e influido ya por el mesianismo salvífico y profético de Ernst Bloch tratará Lukács de formar con sus amigos en las cercanías de Heidelberg una comunidad de vida. Bastan estas referencias para caer en la cuenta del carácter 
romántico del anticapitalismo del primer Lukács. Pocos vivenciaron tan profundamente como él la decadencia del mundo arisiocratizante y gentry de la "Hungría hisiórica" de Francisco José. Pocos expresaron tan existencialmente esta vivencia como lo hiciera Lukács en Historia del drama y en El alma y las formas. Lukács se identificó con el decaer, nucleó su vida en la vivencia de lo trágico y estuvo varias veces al borde del suicidio por no saber a qué atenerse. Su posterior franciscanismo (Lukács acude en actitud peregrinante a la iumba de Francisco de Asís), su apego a la obra como tablá de salvación frente a la caótica multiplicidad de la vida, su reflexión sobre la inquebrantabilidad de las castas, su deseo de retirarse a las afueras de Heidelberg para formar allí una comunidad, su adhesión al revolucionarismo sin revolución del poeta húngaro Endre Ady y el revolucionarismo interior de Dostoievski, su apertura al sindicalismo de tipo soreliano y a las posiciones de Rosa Luxemburgo... no son sino manifestaciones de una búsqueda marcada por el anticapitalismo romántico. La vida era para él trágica, pero su tragicismo era sobrehumano porque, dada su procedencia social (la más alta burguesía financiera) y su formación elitizada, el juego de las fuerzas en lucha le impedía vislumbrar caminos de salida. No aceriaba a ver otro camino para la realización en plenitud de la posibilidad humana sino el apego al tragicismo como forma de vida y a la obra como tabla de salvación, como signo de la permanencia en el cambio, como cosmos frente al caos de la vida toda. Ni el neoabsolutismo gubernamental. (que tanto beneficiara a los Lukács económica y socialmente: swopadre recibió el lítulo de nobleza en 1901), ni el radicalismo burqués de las capas medias (en cuyas filas se sintió siempre Lukács sólo "huésped tolerado"), ni el movimiento obrero (dirigido todavía por la socialdemocracia $y$, por lc. mismo, plagado de resabios pequeño-burgueses) parecían responder a las expectativas del filósofo. Hacia 1910 los caminos se cierran a los pies de Lukács. De poco le sirven los consejos pragmatistas del padre, el banquero József von Lukács, quien estaba empeñado en hacer de su hijo predilecto un prestigiado intelectual. "Porque mira, hijo mío - le dice en una carta del 2 de julio de 1910-, los éxitos externos, los resultados externos también son muy importantes en la vida... Vería con mucho gusto, por tanto, que en Weimar consigueses la publicación en alemán de tu gran libro... Después de que aparezca tu gran libro harías bien en dedicarte de inmediato a conseguir la habilitación como profesor..." Le promete incluso mover sus influencias para conseguir una cátedra, y hasta le ayuda económicamente para que publique luego la revista $A$ szollem (El espíritu). Pero el joven György Lukács no comulgaba con los buenos deseos de su padre. Le son también poco úties la amistad de Béla Balázs y Endre Ady 
e incluso la estrecha relación con Irma Seidler. Una soledad radical, de la que Historia del drama es la primera expresión, va anidando en su espíritu como polo negativo de una radical necesidad de comunicación. La crisis, conceptual y vivencial a un tiempo, se expresa con maestría en El alma y las formas y llega hasta honduras insospechadas en el Diario (inédito de 1910-1911) y en el diálogo titulado "Acerca de la pobreza de espíritu" (este diálogo fue motivado por el suicidio de Irma Seidler, quien se suicidó precisamente por interpretar el retiro de Lukács -al modo del "gesto" de Kierkeggard frente a Regina Olsen- como un rechazo). Pero ya en "Acerca de la pobreza de espíritu" se vislumbra un camino de salida que se irá afirmando en Filosofía del arte (1912-1914), en La teoría de la novela (1916) y en Estética de Heidelberg (1916-1918). Se trata de un camino que tiene que ver con la llegada al límite y con la incursión en el horizonte de lo utópico. Si la identificación con la tragicidad como forma de vida es en Lukács muestra de su actitud de rechazo frente a la sociedad burguesa, su incursión en el horizonte de lo utópico le conducirá a las puertas del socialismo. $Y$ en el camino de Lukács hacia Marx su primera obra, Historia de la evolución del drama moderno, es un paso fundamental en cuanto que marca el inicio de la ruptura con el mundo capitalisia del que provenía y cuya ideología constituía la base de su primer filosofar.

\section{BIBLIOGRAFIA}

Nota. No parece hecesario alargar el trabajo con las acostumbradas referencias bibliográficas y documentales por tratarse de textos en húngaro que poco o nada plieden decir al lector de habla hispana. Baste, pues, con la siguiente anotación general:

Lukács, György - A modern dráma fejlödésének története (Historia de la evolución del drama moderno). A Kisfaludy-Társaság Lukács Krisztina-dijával jutalmazott pályamú (Obra galardonada con el premio "Cristina Lukács" de la Sociedad Kisfaludy). Budapest, Franklin-Társulat, 1911. 2 volúmenes, XVI $+496+548 \mathrm{p}$.

Lukács, György - Magyar irodalom - magyar kultúra. Válogatott tanulmányok (Literatura húngara - cultura húngara. Estudios escogidos). Budapest, Gondolat Kiandó, 1970. Ver especialmente el prólogo escrito por Lukács en Budapest en 1969.

Fehér, Ferenc - Balázs Béla és Lukács György szövetsége a forradalomig (Alianza de Bla Balázs y György Lukács hasta la revolución). Irodalomtörténet (Historia de la literatura). Revista de la Sociedad Húngara de Historia de la Literatura. Budapest, año LI, núm. 2, 1969; p. 317-347 y 531-561.

Hermann, István - Lukács György gondolatvilága. Tanulmny a XX. század emberi lehetöségeiröl (El mundo intelectual de György Lukács. Estudio acerca de las posibilidades humanas del siglo XX). Budapest, Magvetö, 1974. 415 p.

Heller, Agnes - Portrévázlatok az etika történetéböl (Bosquejos de historia de la ética). Budapest, Gondolat, 1976. 433 p. 
Márkus, György - A lélek és az élet: a fiatal Lukács és a "kultúra" problémája (El alma y la vida: el joven Lukács y el problema de la "cultura"). Magyar Filozófiai Szomle (Revista Húngara de Filosofía). Budapest, año XVII, n. 5/6, 1973. p. 742-760.

Lukácshoz irt levelek: 6 Balázs Béla (1910-1917) (Cartas escritas a Lukács: 6 Béla Balzs). Academia de Ciencias de Hungria. Instituto de Filosofía. Archivo y Biblioteca Lukács.

Lukácshoz irt levelek: 71 Lukács József (1909-1917) (Cartas escritas a Lukács: 71 József Lukács). Academia de Ciencias de Hungría. Instituto de Filosofía. Archivo y Biblioteca Lukács.

Lukács, György - Naplójegyzetek (Diario): 1910-1911. Se trata de un cuaderno manuscrito que consta de 55 páginas, escrito en húngaro y en alemán. El cuaderno se conserva en el Archivo y Biblioteca Lukács de Budapest.

Balázs, Béla - Naplói (Diarios). Se trata de un manuscrito de Béla Balázs que se conserva en la Sección de Manuscritos de la Academia de Ciencias de Hungría. 